\title{
The Effect of Peer Communication Influence on the Development of Materialistic Values among Young Urban Adult Consumers
}

\author{
Eric V. Bindah, PhD Scholar (Corresponding author) \\ Faculty of Business \& Accountancy Building, Department of Marketing \\ University of Malaya, 50603 Kuala Lumpur, Malaysia \\ Tel: 60-12-679-5045 E-mail: bindahe@yahoo.co.uk \\ Md Nor Othman \\ Professor and Head of Marketing Department \\ Faculty of Business \& Accountancy Building, University of Malaya \\ 50603 Kuala Lumpur, Malaysia \\ E-mail: mohdnor@um.edu.my
}

Received: December 15, 2011

Accepted: January 17, 2012

Published: March 1, 2012

doi:10.5539/ibr.v5n3p2

URL: http://dx.doi.org/10.5539/ibr.v5n3p2

\begin{abstract}
The study attempts to uncover the characteristics of materialism groups in Malaysia among young adult consumers. It assesses the differences between materialism groups, i.e., low and high materialistic groups, using demographic and peer communication dimensions. The data was collected through self-administered questionnaires. The sample consisted of 956 respondents. The majority of the respondents were Malays followed by Chinese and Indians. The proportion of female respondents was higher than the male respondents. Most of the respondents were single and in the age group of between 19-29 years old. Independent sample t-tests were used to compare mean scores for the study variables between 'high' materialism and 'low' materialism groups and significant mean differences were found between 'high' and 'low' materialism groups in terms of peer communication construct. Specifically, it was found that the 'high' materialism group has considerably greater ratings on the construct. Internal consistency reliability assessment using Cronbach coefficient alpha revealed that the two dimensions had high reliability. A stepwise discriminant analysis performed on peer communication variable found that peer communication variable was significant in differentiating the two materialism groups. The implications, significance and limitations of the study are discussed.
\end{abstract}

Keywords: Materialism group, Demographic profile, Peer communication, Discriminant analysis

\section{Introduction}

Studies on consumer socialization have identified eight major socialization agents in most modern societies (Reimer \& Rosengren, 1990). Previous studies on consumer socialization identified traditional socialization agents as family, peer group, work group, church, law and school; they can be found in most societies (Bindah \& Othman, 2011; Reimer \& Rosengren, 1990). People often interact with socialization agents and then take in consciously and unconsciously social norms, values, beliefs, attitudes and behaviors endorsed by these agents (Croteau \& Hoynes, 2000). As postmodern society grows more and more atomistic, individualistic and alienated, socialization agent becomes more and more powerful (Croteau \& Hoynes, 2000). Ward (1974) offered a classical definition of consumer socialization: "the processes by which young people acquire skills, knowledge and attitudes relevant to their functioning as consumers in the marketplace," (p. 2). The skills, knowledge and attitudes directly relevant to consumption behavior are "those which are necessary for enactment of the consumer role-for example, skills at budgeting, pricing, knowledge of brand attitudes and shopping outlets, and attitudes toward products, brands, and sales people,"(Ward, 1974, pp. 2-3). Materialism among today's youth has also received strong interest among educators, parents, consumer activist and government regulators for many reasons (Korten, 1999). For instance, many studies on materialism among college and high school students show dramatic increases in materialistic values (Korten, 1999). Furthermore, the popular press has also characterized youth as "hyper-consumers." Social scientists 
have responded with a burst of recent books that decry materialism among young consumers and criticize marketing's role in the development of materialistic values (Kasser, 2002; Schor, 1999).

Although materialism has long been of interest to consumer researchers, surprisingly however, with such a growing concern about adolescent becoming too materialistic, research into this area has paid little attention to young adult consumers and their endorsement of materialistic values. Kau et al. (2000) for instance, have examined if the level of materialistic inclination differs among respondents with different demographic characteristic. Using a sample of undergraduate students in the age group of 15 to 54 years old, the findings revealed that people in different age group were observed to differ in their degree of materialistic inclination. In their study, teenagers in the age group of between 15 to 19 years old were less materialistic; their older counterparts in the age group of 20 to 29 years old were more materialistic. A major limitation of previous studies into the effects of socialization agents has been the limited scope of the analyses, confined to a given developmental stage (for example, childhood, adolescents). Cross sectional data analyzed at a specific development stage in a person's life tell us little about the possible casual influences of socialization agents, living room for criticisms about the nature and direction of influence between materialism and measures of the person's interaction with socialization agents (Moschis, 1985). Furthermore, it is not clear whether specific socialization agents in general, and communication environment in particular, can instill materialistic values in people.

There exist several definitions of young adults. Theorists often define young adults as those who have reached sexual maturity, but are not married (Schindler, 2001). Custom in the United States distinguishes young adults as those newly eligible to vote, at age eighteen. Erikson (1968) devoted his research to defining the eight stages of life. Young adulthood, according to his model, falls in the sixth stage, "intimacy vs. isolation." The developing person grows up until the time he/she forms his/her identity. Then is the test to see if the individual can fuse his/her identity with that of others, and if the person is ready for intimacy, and the capacity to commit himself or herself to concrete affiliations and partnerships (Erikson, 1968). This stage can only occur after the person has successfully completed the other stages. Often, chronology of age is not the most important consideration. Studies analyzing consumer behaviour have fundamentally focused on adolescents, and their findings have generally not been transferable to young adults (Ganassali et al. 2006). The reason to study young consumer is due to young behaviour represents a collective subject holding a common culture (Fabris, 2003): this common culture is based on some shared values, on a shared tendency to feel as citizens of the world, on a common propensity to experience new things and to support new ideas. From this point of view, young consumer behaviour is a relevant issue for managers and policy makers too, because they are recognized as a significant market segment (Moschis \& Moore, 1979) and they frequently represent the pioneers of new social and consumption trends. The study of young people behaviour is consequently of great interest, given the significant spending of this segment of the population and the importance of their purchases (McNeal, 1999).

Most research conducted in the area of consumer socialization and its effect on the development of materialistic values, have placed their emphasis on the key relationships between variables in their model, with very few exceptions of studies addressing distinct materialism groups among socialization agents (e.g., Goldberg et al., 2003). Research addressing specific distinct materialism group differences across peer communication has not been explored extensively. Hence, there is a need to examine the differences of peer communication factors across distinct materialism subgroups and to identify the important factor in discriminating between these materialism groups. The purpose of this paper is to adopt a theoretical framework to explain the mechanism responsible for the development of materialistic values among young adult consumers. This paper emphasized on the role of peer communication influences on the development of materialistic values among young adult consumers. Based on theoretical and research perspectives, two hypotheses are developed.

\subsection{Objectives of Study}

a. To examine the differences between low and high materialism groups among young urban adults consumers in Malaysia using demographics dimension.

b. To examine the differences between low and high materialism groups among young urban adults consumers using peer communication dimension.

\section{Literature Review}

When it comes to consumer socialization, attitudes, aside from values (e.g., materialism), behaviours and norms are important elements in the study of the consumer socialization process as defined by Ward (Ward, 1974). Among the major sources of socialization influence, include parents, peers, media and school. Prior research identify parents are the main agents in children and adolescents' primary socialization process, in which implicitly and explicitly they teach and transmit consumer-related orientations to their child (e.g., John, 1999; Ward, 1974). According to Moschis 
(1985), in the secondary socialization process, peers, school and media tend to gain influence (Moschis, 1985). Marketing and advertising scholars have found that at the perceptual stage (2 to 7 years old) (Piaget, 1953), young children's consumer learning mainly comes from their modeling on parents and peers while the influence of mass media is low (Ward \& Wackman, 1971).

Researchers have also found that children in the critical period (7 to 11 years old) (Piaget, 1953) can recognize the functional differences between program and commercials and they can distinguish program from commercials based on persuasive intent (Blosser \& Roberts, 1985; Robertson \& Rossiter, 1974). Children in the critical period can recall both visual and verbal details of television commercials, and they can recall more brand names (John, 1999). They begin to perceive some bias and deception in advertising messages and accordingly foster a more negative attitude toward advertising (John, 1999). They can categorize products and discriminate brands according to their underlying functional attributes (John \& Lakshmi-Ratan, 1992).

For teenagers in the reflective period (11-17) (Piaget, 1953), observational learning has become the most important device of their consumer socialization. They turn away from parents to peers and seek consumer information from various mass media. They learn consumer knowledge and skills through direct experiences (trial), observation (imitation), and vicarious experiences.

Previous research suggests that, as socializing agents, television and peers are more important than family for adolescents while young teenagers are more sensitive to the social meaning of consumption because of their strong self-expressive orientation (Churchill \& Moschis, 1979; Moschis \& Churchill, 1978; Moschis \& Moore, 1979; Moschis \& Mitchell, 1986). Social structural restraints including social class, gender and race, have also been examined by many scholars as antecedent variables of adolescents' consumer socialization and they are found to be interesting mediators, facilitators or limiting factors, but family, peers and mass media have always been identified as dominant influences (Churchill \& Moschis, 1979; Moschis \& Churchill, 1978; Moschis \& Mitchell, 1986). Thus, aside from television and family influences, previous research indicates that peer as a socialization agent plays a significant role in influencing adolescent in many aspects of their consumption behaviour, norms and values. Given the importance of the role peers exert on adolescents as they grow up into adulthood, it is interesting for marketers and scholars to understand just how much or to what extent peers play a significant role in influencing young adults' development of values, such as materialism. The present study attempt to explore peer influence, particularly the communication and interaction patterns that takes place between young adults and their peers to determine if there is any implication on the endorsement of materialistic values. Churchill and Moschis (1979) have offered a general conceptual framework that is useful in organizing and conceptualizing variables for the study of consumer socialization, and has applied the general theoretical and conceptual notions of socialization to the specific context of consumer socialization.

Although no single set of socialization concepts, assumptions, and hypotheses has been agreed upon to guide research efforts in the area of consumer socialization, a rough blueprint does exist outlining what data should be included and what a socialization theory of consumer behaviour might look like and is adapted for the present study. McLeod and O'Keefe (1972), for example, maintained that a complete socialization theory must deal with five types of variable: (1) content or criterion behaviour; (2) agent or source of the influence; (3) learning processes involved in socialization; (4) social structural constraints affecting learning; and (5) age or life cycle position of the person being influenced (Churchill \& Moschis, 1979). The following provides a brief explanation on the five different types of variables.

\subsection{Content or Criterion Behavior}

Socialization research focuses on the study of the development of learning properties (cognitions and behaviours) necessary for the performance of a given social role (Churchill \& Moschis, 1979). Learning properties can be divided into: (1) properties that help a person function in any given social system and (2) properties related to a person's individual behaviour regardless of the standards set by any larger system (McLeod \& O'Keefe, 1972; Churchill \& Moschis, 1979). The criteria relevant to the functioning in any given social system are prescribed by that society. They are based on normative theories of human behaviour and, are efforts on the part of some members of that society to regulate the behaviour of other members so that certain "desirable" consequences follow (Churchill \& Moschis, 1979). Criteria relevant to individual behaviour, on the other hand include cognitions and behaviours that enable the person to enact a given social role, regardless of whether the behaviours are functional or dysfunctional in any larger system.

\subsection{Agent or Source of Influence}

Socialization is often viewed as a social process by which norms, attitudes, motivations, and behaviours are transmitted from specific sources, commonly known as "socialization agents" to the learner (Churchill \& Moschis, 
1979). "Socialization takes place through interaction of the person and various agents in specific social settings" (McLeod \& O'Keefe, 1972, p. 135). A socialization agent may be a person or an organization directly involved in socialization because of frequency of contact with the individual, primacy over the individual, and control over rewards and punishments given to the individual (Churchill \& Moschis, 1979). These agents are of high salience to the learner and continue to influence the development of his/her character, even as new agents are added and older ones are displaced. The result of these interactions is the development of a series of "self-other systems" in which the individual is oriented toward the evaluations of significant others and the role prescriptions (Churchill \& Moschis, 1979).

The main implication of including specific-influence agents in the socialization model is that the unit of analysis becomes the agent-learner relationship (McLeod \& O'Keefe, 1972). Talmon (1963) classifies these agent-to-learner relationships into four categories on the basis of the formality of the type of agent and the role of the learner: (1) formal organization (agent), role of learner specified (e.g., school); (2) formal organization, role of learner not specified (e.g., mass media); (3) informal organization, role of learner specified (e.g., family): (4) informal organization, role of learner not specified (e.g., peers).

\subsection{Learning Processes}

The processes by which the learner acquires specific values and behaviours from the socialization agents, while interacting with them, can be divided into three categories: modeling, reinforcement, and social interaction (McLeod \& O'Keefe, 1972).

\subsubsection{Modeling}

Modeling explanations involve imitation either through a conscious attempt to emulate the socialization agent or because the agent's behaviour is the most salient alternative open to the person (McLeod \& O'Keefe, 1972; Churchill \& Moschis, 1979). For example, adolescents do the same things as their peers do in an effort to be like them. This type of learning process has also been referred to as observational and imitation learning (Churchill \& Moschis, 1979).

\subsubsection{Reinforcement}

These explanations of learning involve either reward (positive reinforcement) or punishment (negative reinforcement) mechanisms.

\subsection{Social Interaction}

The social interaction mechanism is less specific as to the exact type of learning involved. It may involve a combination of modeling and reinforcement (McLeod \& O'Keefe, 1972; Churchill \& Moschis, 1979). This explanation holds that the characteristic social norms involved in the person's interactions with other significant persons shape the individual's attitudes, values, and behaviour. Thus, what is learned is a series of interpersonal relationships relating to a given social role (Thorton \& Nardi, 1975). The social interaction process may have content and structure. Content often refers to expectations (norms) held by agents as to what the prescribed role should be; these may be attitudinal, behavioural, or cognitive (Thorton \& Nardi, 1975). The structure of the social interaction mechanism, on the other hand, usually refers to agent-child relations concerning power and communication.

\subsection{Social Structural Constraints}

Social structural explanations of socialization emphasize the person's social environment within which learning takes place. Social variables such as social class, sex, and birth order can have a direct as well as indirect effect in socialization, by influencing learning processes (McLeod \& O'Keefe, 1972; Churchill \& Moschis, 1979).

\subsection{Age or Life Cycle Position}

Although the study of socialization was once restricted to learning that takes place during childhood, it has been extended in recent years to include the study of learning that occurs throughout a person's lifetime (Churchill \& Moschis, 1979). Because people learn continuously and because they learn different things at different times in their lives from different agents, the emphasis is on changes in a person's cognitions and behaviours as the individual moves through the life cycle, specifically in the post-adolescent period when the person gets married, takes a job, and so forth, at different ages (Churchill \& Moschis, 1979). Theory and research also suggest that people at different age or life cycle levels may be influenced differently by environmental factors, e.g., socialization agents (Churchill $\&$ Moschis, 1979). Thus, all generalizations are dependent upon a particular phase in the developmental process or life cycle, and a different cluster of variables tends to dominate each stage. 
Typical research on development of consumer patterns of thinking and behaving has been based on two models of human learning: the cognitive developmental model and the social learning model. Studies utilizing the cognitive developmental approach attempt to explain socialization as a function of qualitative changes (stages) in cognitive organization occurring between infancy and adulthood. Stages are defined in terms of cognitive structures the child can use in perceiving and dealing with the environment at different ages. As the child "moves" from one stage to another, $\mathrm{s} / \mathrm{he}$ is assumed to be developing and integrating various learning properties. The social learning model, on the other hand, seeks explanations for the formation of cognitions and behaviours from the sources of influence (socialization agents) transmitting attitudes, motivations, and values to the person. Learning is assumed to be taking place during the person's interaction with these socialization agents in various social settings (McLeod \& O'Keefe, 1972; Churchill \& Moschis, 1979).

\subsection{Materialism}

In the relevant literature, materialism is defined from various social, cultural, psychological, and economic perspectives: a way of life, a value orientation, a cultural system, a personality trait, a second-order value, an aspiration (e.g., Daun, 1983; Fox \& Lears, 1983; Ward \& Wackman, 1971; Inglehart, 1981; Mukerji, 1983; Belk, 1984; Richins \& Dawson, 1990; Bindah \& Othman, 2011). Daun (1983) described materialism as a lifestyle in which a high level of material consumption functioned as a goal and served as a set of plans. Materialism lends meaning to life and provides an aim for everyday work. Fox and Lears (1983) regarded materialism as the ceaseless pursuit of the "good life" through consumption. Ward and Wackman (1971) defined materialism as "an orientation which views material goods and money as important for personal happiness and social progress" (p. 422). And Inglehart (1981) considered materialism as an economic orientation to life, a cultural or structural variable, giving precedence to economic values over other values such as freedom, civil power, aesthetics, and friendship. He argued that materialism was a value situated within the constellation of a value system. Similarly, Mukerji (1983) regarded materialism as a cultural system in which material interests are not made subservient to other social goals and material self-interests are prominent. Belk (1984) observed, "Materialism reflects the importance a consumer attaches to worldly possessions. At the highest levels of materialism, such possessions assume a central place in a person's life and are believed to provide the greatest sources of satisfaction and dissatisfaction," (p. 291).

More relevant to this paper, Richins and Dawson (1990) considered materialism as a value orientation with at least three components: a status component, which reflects the intended and actual use of material objects as a means of social recognition and to symbolize one's personal success; the expectation or aspirational component of materialism concerns the extent to which an individual believes that acquisitions of material objects will lead to personal happiness and enjoyment of life; and an affective component represented by the degree to which an individual actually does find possessions to be a source of satisfaction. Materialism is an organizing or second-order value that incorporates both the importance placed on certain end states (achievement and enjoyment values) and beliefs that possessions are appropriate means to achieve these states (Richins \& Dawson, 1990).

Richins and Dawson's (1992) concept of materialism rests on the two processes of acquisition and possession. They believe that these processes organize and guide the materialist's plans and behaviours under the expectation of certain favourable end states. There are three themes in their concept of materialism. First, acquisition is central to the lives of materialists. It not only serves as a focal point, but also organizes behavioural patterns. Acquisition serves as a set of plans and goals that directs and guides daily endeavours. Second, acquisition is a means of achieving happiness and well-being in life. To materialists, both acquisition and possession of goods are essential to satisfaction and well-being in life. Finally, materialists use possessions to display success or status. They judge their own and others' success by the number and quality of possessions accumulated. They view themselves as successful to the extent they can possess products that project the desired self-image. Materialism represents a mind-set or constellation of attitudes regarding the relative importance of acquisition and possession of objects in one's life. For materialists, possessions and their acquisition are at the forefront of personal goals that dictate their "way of life." They value possessions and their acquisition more highly than most other matters and activities in life. For Richins and Dawson (1992), materialism is a value that guides people's choices and conduct in a variety of situations, including, but not limited to consumption areas. It should be able to influence not only the type of products purchased, but also the quantity.

This paper follows that of Richins and Dawson (1992) to define materialism as a value of at least three components: acquisition centrality, acquisition as the pursuit of happiness, and possession-defined success. It is an organizing central value that guides people's choices and behaviour in everyday life. It is an enduring belief that acquisition and possessions are essential to happiness and success in one's life. Broadly defined, materialism is any excessive reliance on consumer goods to achieve the end states of pleasure, self-esteem, good interpersonal relationship or 
high social status, any consumption-based orientation to happiness-seeking and a high importance of material issues in life (Ger \& Belk, 1999).

\subsection{The Relationship between Peer Communication Influence and Materialism}

In the consumer context, many aspects of socialization, including an understanding of materialism, arise from peer communication. It has been recommended that research along these lines be furthered by breaking down peer relationships into factors such as frequency of interaction and communication. In this study, peer communication is investigated to capture its effect on the development of materialism among young adult consumers.

There are very few and well established researches conducted in the area of peer communication and influences and its relationship with materialism (e.g., Moschis \& Churchill, 1978; Churchill \& Moschis, 1979). Most previous researchers either focused on children or adolescents, and practically no research has examined the effect of peer communication and influences of young adults and its relationship with materialism. Moschis and Churchill (1978) have examined the influence of family communication, on youth's development of specific consumer related motives and values in the context of consumer socialization among adolescents within the age group of (12 to 18 years old). It was reported that adolescent peer groups were particularly significant sources of influence. Children learned from peers "expressive elements of consumption" or "affective consumption" ("styles and moods of consumption"). In the study, the researchers hypothesized that the more frequently an adolescent communicated with their peers about consumption matters, the more positive the individual's materialistic attitudes would be. The result of the study indicated that the correlation between peer communication about consumption and materialistic values was positive and statistically significant and thus suggesting that youths may learn the expressive aspects of consumption from their peers. Adolescents appeared to acquire several cognitive skills by interacting with their peers. Peer communication about consumption variable was related positively to the adolescent's and materialism. Churchill and Moschis (1979) conducted another research with adolescents from both urban and rural areas with respect to peer communication about consumption, in which the researchers hypothesized a positive relationship between the adolescent's frequency of communication with his/her peers about consumption matters and the strength of his/her materialistic attitudes. Their findings indicated that materialistic values increase with the extent of peer communication. Their research findings also indicated that peer influence may be of significance in situations involving conspicuous consumption. These speculations and findings supported a hypothesized positive relationship between the adolescent's frequency of communication with his/her peers about consumption matters and the strength of his/her materialistic attitudes.

Moore and Moschis (1981) have studied the influence of peers as socialization agents and the effects of demographics variables on adolescents' consumer learning within the context of a conceptual model of consumer socialization. In their study, materialism was included as part of the consumer learning properties. The researchers hypothesized that the more frequently an adolescent communicated with peers about consumption matters, the more positive the individual's materialistic attitudes would be. The result was significant. It was found that the frequency of peer communication seems to lead to the development of materialistic orientations. The researchers concluded that the expressive aspects of consumption may be acquired from peer. Later, Achenreiner (1997) conducted a study to examine the materialistic attitudes of children across a wide age span, using a large sample, and a multi-item materialism scale, and examined the relationship between materialistic attitudes in children and susceptibility to peer group influence. The materialistic attitudes of children, ranging in age of 8 to 16 year old were examined using a multi-item materialism scale for children. The findings indicated that materialism was a relatively stable trait, varying only marginally with age, despite the numerous developmental changes taking place as a child gets older. The study also examined the relationship between materialism and susceptibility to peer influence and found a significant correlation. The findings supported the hypothesis that materialism and susceptibility to influence were positively related. The research was critical for a better understanding how materialistic attitudes develop and the role peer influence had on these attitudes. Regardless of age, children who were higher in susceptibility to influence also tended to be more materialistic. Flouri (1999) have examined the extent to which family environment mediate the relationship between family structure, religious attendance susceptibility to interpersonal influence communication with peer about consumption and materialism among mothers with children from college students aged between 16 to 23 years old. The results indicated that materialism was positively related to communication with peers about consumption issues. Materialism was independently predicted by the extent of peer influence. Materialism in adolescents was positively related to communication with peers about consumption issues and susceptibility to interpersonal influence. However within a maternal sample, adolescents' materialism correlated with peer influence. The results also showed that materialism in adolescents was independently predicted by the extent of peer influence. In another study, Chan and Prendergast (2007) surveyed adolescents aged 11 to 20 to ascertain whether adolescents in Hong Kong endorsed materialistic values, and to examine the influences of 
interpersonal communication on adolescents' tendency to engage in social comparison and endorse materialistic values. They found that peer communications were positive predictors of social comparison with friends, and that peer influence had a positive correlation with materialism. The findings also indicated that normative peer influence was related to social comparison with friends while informative peer influence was not.

On the other hand, Chan and Zhang (2007) have examined the influence of peers and media celebrities on young people's endorsement of materialistic values in China. As the Chinese culture is said to be collective, it was expected that social relations, both personal and celebrity-mediated, played an important role in the establishment of consumption values. The respondents for the study were university students aged 18 to 24 years old in Beijing. The results indicated that peer communication and susceptibility to peer influence were positively related to social comparison. Motivation for viewing advertisements was positively related to imitation of celebrity models. In turn, both social comparison and imitation of celebrity models were positive predictors of materialism. The results of their study revealed that peer communication was positively correlated with social comparison. The level of peer communication reflected the frequency of peer interaction. Respondents who frequently communicated about advertisements and consumption with friends were more likely to engage in social comparison, because much of their communication is about possessions and brands. Social comparison in turn had a positive correlation with materialism. Respondents who compared their possessions with the possessions of friends and media celebrities came to believe that possessions were related to success and happiness, and that possessions occupy a central position in life. The findings of the study was also interpreted as showing that those who placed a high importance on material possessions were keen to engage in social comparison and peer interaction. The study has shown that when youth have higher levels of communication with peers, and were more vulnerable to their influence, they tended to engage in social comparison more often. And, this in turn predicted their level of materialism.

La Ferle and Chan (2008) have examined the influence of marketing communication factors, specifically social influences factors, peers on adolescents' endorsement of materialistic values in Singapore, with adolescents age 13 to 18 years old. They found that respondent would seek advice from peers when they buy products. In the study peer influence explained $40 \%$ of the variance in materialistic values, and was found to be significant predictors of materialistic values among adolescents. Multiple regression analysis indicated that peer influence were positive predictors of materialistic values. Respondents who perceivedhigher level of peer influence were more materialistic. The study indicated that social influences played an important role in predicting levels of materialism among adolescents in Singapore. Furthermore, Roberts, Manolis and Tanner (2008) have investigated adolescents susceptibility to parental and peer influences, and how this susceptibility impact materialistic values and compulsive buying, using a sample of adolescents from grade 7 through 12 whose ranged aged were from 11 to 19 years old. The results of their study indicated that normative peer influence was shown to increase the level of materialism. Based on the background study, the following hypotheses are developed to identify factors that distinguished 'high materialism' and 'low materialism' groups, and to determine the relative importance of these factors in predicting group membership.

Ho1. Young adults who score 'high' on materialism tend to have a higher score on peer communication.

Ho2. Young adults who score 'low' on materialism tend to have a lower score on peer communication.

\section{Methodology}

The following section mainly provides a discussion on the sample procedures and measurement and reports the inter-item reliability of the main constructs.

\subsection{Sample and Procedures}

Materialism and peer communication amongst young adults were examined through a survey conducted in the Klang Valley in Malaysia from January to March 2011. The target population were college students in public universities and private colleges of higher learning across the Klang Valley region in Malaysia as most institutions of higher learning in the country are concentrated in this area. College students were chosen for the study because generally they represent the future of a country because, with a good education, most of them will become middle-class professionals. On the other hand, most well-educated college students in the future will become relatively high-income professionals and spend much more money on products or services. Understanding their values and inclinations is useful for predicting the purchase patterns of young Malaysian working professionals. In total, 956 completed the survey questionnaires and were usable for the data analyses.

\subsection{Measures}

Allthe constructs were measured by multiple items. Generally, the respondents were asked to indicate on a five-point scale the extent to which they agreed with the statements ( $1=$ Somewhat disagree, $5=$ Strongly agree). 
Demographics variables were also collected and included gender, age, ethnicity, religion, marital status, and gross personal monthly income.

\subsubsection{Materialism}

Our key constructs were assessed using previously published, multi-item measures using a five-point Likert format adapted from Richins and Dawson (1992). As a means of testing the Material Value Scale (MVS) cross-cultural applicability using an alternative format, we followed the recommendations of Wong et al. (2003) by replacing the MVS's mixed-worded Likert format with a 15-items interrogative question format. Thus, rather than forcing respondents to agree or disagree with statements (e.g., I admire people who own expensive cars, homes, and clothes), we asked respondents to react to questions (e.g., How do you feel about people who own expensive cars, homes, and clothes?) using a set of specific response options (e.g., do not admire vs. greatly admire). We altered the direction (i.e., left or right side) of these anchors to mirror the original direction of the Likert-style MVS (MVS-Likert). The inter-item reliability (Cronbach's alpha) was 0.69 . The mean formed the measure of materialism, with higher scores indicating stronger endorsement of materialistic values.

\subsubsection{Peer Communication}

Peer communication was operationally defined as the overt peer-young adults' interactions about goods and services. Peer communication was measured with three items in which respondents were asked about the extent to which they interacted with their peers with regards to their buying habit and indicated the extent to which they agree or disagree with the statements. The items were adapted from Moschis and Moore (1979) which originally consisted of three items and were then modified for the study. The original scale response were recorded on a 5-point Likert scale ranging from 1 'Very' to 5 'Never,' whereas we have modified the scale and responses are recorded on a 5-point Likert scale ranging from 1 'Strongly disagree' to 5 'Strongly agree.' The reason for modification was to standardize the scale for the various sections of the questionnaire and to encourage consistency in responses. The statements were: "My friend and I talk about buying things," "My friend and I learn from each other about buying things," "My friend and I trust each other about buying things." The inter-item reliability (Cronbach's alpha) was 0.69.

\section{Results}

\section{1 'High' Materialism and 'Low' Materialism Groups: A Demographic Comparison}

The subjects of this study were classified into two materialism groups. That is, respondents who tend to agree more with the materialism statements were classified as 'high' materialism; those respondents who did not agree much with the statements were categorised as 'low' materialism. The classification of high and low materialistic values among young adults, is based on previous study conducted by Goldberg et al. (2003) on materialism among young adults, where their analyses were conducted by dividing the sample into quartiles and focusing on youths who were the most and least materialistic-those in the highest quartile and lowest quartile. The analysis in the study conducted by Goldberg et al. (2003) follows that of Richins (1994) who used the bottom and top quartiles of scores on her Adult Materialism Scale to classify respondents so as "to achieve a clear separation" (p. 524). Similarly, Richins and Dawson (1992) compared the top and bottom terciles. This approach is akin to the "known groups" approach (Wiggins, 1973). Because it is known with relative clarity what to expect of those who fall at either end of the scale, we focus on a comparison between them. In contrast, it is not so clear what to expect for those closer to the middle of the scale and so it is harder to predict how they will score on the various criterion measures.

Chi-square tests of independence were used to examine the demographic differences between 'high' materialism group and 'low' materialism group. Among the demographic variables, however, no significant differences were found between 'high' materialism and 'low' materialism groups. Table 1 presents the Chi-square results for the present study.

Insert Table 1 Here

\section{2 'High' and 'Low' Materialism Groups: Comparing the Peer Communication Factor}

Independent sample t-tests were used to compare mean scores for the study variables between 'high' materialism and 'low' materialism groups. As shown in Table 2, the present findings are encouraging whereby significant mean differences were found between 'high' and 'low' materialism groups in terms of peer communication factor. Specifically, it was found that the 'high' materialism group has considerably greater ratings on all constructs.

Insert Table 2 Here

From the independent sample t-tests analysis, a profile of 'high' and 'low' materialism groups can be drawn up. Specifically, young adults who tend to communicate with their peers with regards to consumption matters tend to be more inclined towards 'high' materialistic values in comparison to 'low' materialistic values. This result converge 
with the findings of Churchill and Moschis (1979), which found in their study that materialistic values did increase with the extent of peer communication. The researchers tested the hypothesis that young people may pay attention to television commercials and discuss them with their peers. They found that materialistic values did increase with extent of peer communication. Another study also converged with our present findings, where Moore and Moschis (1981) surveyed 784 respondents from sixth through twelve grade students. Their findings indicated that the frequency of peer seems to lead to the development of materialistic orientations. Thus, concluding that the expressive aspects of consumption may be acquired from peers. Flouri (1999) who surveyed 246 adolescents aged 16 to 23 years old have found that materialism was positively related to communication with peers about consumption issues. Materialism wasindependently predicted by the extent of peer influence. Materialism in adolescents was positively related to communication with peers about consumption issues. Their results showed that materialism in adolescents was independently predicted by the extent of peer influence. In China, Chan and Zhang (2007) surveyed 305 university students (undergraduate and graduate students) aged 18 to 24 and found that peer communication and susceptibility to peer influence were positively related to social comparison. Motivation for viewing advertisements was positively related to imitation of celebrity models. In turn, both social comparison and imitation of celebrity models were positive predictors of materialism. Respondents who compare their possessions with the possessions of friends and media celebrities believe that possessions were related to success and happiness, and that possessions occupy a central position in life. Those who place a high importance on material possessions were keen to engage in peer interaction.

\subsection{Predicting Group Membership: A Discriminant Analysis}

While the significant mean difference tests as discussed above provided a preliminary insight into the differences between the two materialism groups, the use of independent sample t-tests was not able to determine the relative importance of each factor that best discriminates between 'high' materialism and 'low' materialism. Therefore, a discriminant analysis was needed to provide an exploration into the discriminating power of these factors. A total of two variables have been included in the discriminant analysis. These variables include: peer communication and materialism.

\subsection{Analysing Group Differences}

The mean differences between two different groups, namely 'high' materialism and 'low' materialism groups, with respect to peer communication were examined. The results revealed that the group who tended to be less materialistic was significantly different from the group who tended to be more materialistic in terms of the study construct. As expected, the groups mean differences were consistent with the findings reported in the independent sample t-tests analysis (see Table 3). When compared to 'high' materialism, young adults who are less materialistic communicated less about consumption matter with their peers.

\section{Insert Table 3 Here}

Statistically, the higher the F-value of a particular variable, the more important the variable is (Hair et al. 2006). It was found that peer communication is an important predicting variable, with the F-value recorded at 24.337. Wilks' Lambda is another measure of group differences based on individual variable, ascertaining the within group variance with the total variance (Hair et al. 2006). In contrast to F-value, the smaller value of Wilks' $\lambda$ (i.e., near 0 ) indicates that the group means seem to be different, and thus the null hypothesis should be rejected (Hair et al. 2006). It was shown that the Wilks' $\lambda$ values for peer communication were low, reported at 0.975 , leading to significant $p$-value of 0.0000. The results have thus far indicated that peer communication is an important significant factor in discriminating the two materialism groups.

\subsection{Discriminant Function}

Table 4 presents a summary of the discriminant function. There was no discriminant function with the eigenvalue of more than one produced for the two materialism groups. The canonical correlation was 0.196 , when squared value implied that this model could explain $44.2 \%$ of the variance in the dependent variable (i.e., materialism). The standardised function coefficients and the structure matrix measures aid in the interpretation of the relative importance of the variables to the function. The higher the standardised function coefficients for a given variable, the more important the variable is (Hair et al. 2006). It was reported that peer communication (0.738) made a great contribution to the function. Next, when the structure matrix correlation was examined, peer communication was again shown to have high correlation with the function $(0.800)$.

Insert Table 4 Here 
The classification results of the discriminant analysis are presented in Table 5. Approximately $56.5 \%$ of the respondents in 'low materialism' group were correctly classified, while $58.3 \%$ of the respondents in 'high materialism' group were correctly classified.

\section{Insert Table 5 Here}

Overall, $57.3 \%$ of the respondents were correctly classified based on the discriminant function. The classified matrix showed that predictive accuracy of the function was $57 \%$ between the 'high' materialism and 'low' materialism groups. Both hypotheses developed for the study regarding materialism group membership was supported with the use of discriminant analysis. The current findings reported peer communication to be an important factor in discriminating the two materialism groups.

\section{Discussion and Direction for Future Research}

The information presented in this article suggests adequate evidence that peer communication appears to play an important role in consumer socialization, particularly among young urban adult consumers in Malaysia. Generally, young adult consumers appear to acquire a variety of consumption-related orientations skills, and values (particularly, materialistic values) from their peers interaction. The purpose of this paper was to provide a theoretical framework to explain the mechanism responsible for the development of materialistic values among young adult consumers. The role of peer communication influences on the development of materialistic values among young adult consumers was assessed using a sample of young urban adult consumers in Malaysia. First, this study has attempted to examine if there were any differences between low and high materialism groups among young urban adults consumers, using demographics dimension. Second, the study attempted to examine the differences between low and high materialism groups among young urban adult consumers using peer communication dimension. Subjects were classified into two materialism groups. That is, respondents who tend to agree more with the materialism statements were classified as 'high' materialism; those respondents who did not agree much with the statements were categorised as 'low' materialism. Chi-square tests of independence were used to examine the demographic differences between 'high' materialism group and 'low' materialism group. Among the demographic variables, however, no significant differences were found between 'high' materialism and 'low' materialism groups.

Independent sample t-tests were used to compare mean scores for the study variables between 'high' materialism and 'low' materialism groups, and significant mean differences were found between 'high' and 'low' materialism groups in terms of peer communication factor. Specifically, it was found that the 'high' materialism group has considerably greater ratings on all constructs. The two hypotheses tested regarding materialism group membership using discriminant analysis were supported, indicating significant differences between 'high materialism' and 'low materialism' groups based on peer communication construct studied. The findings of the present study suggest that, young adults who communicated and interacted more frequently with their peers about consumption matters are likely to develop more materialistic values. In contrast, young adults who communicated and interacted less frequently with their peers about consumption matters are likely to develop less materialistic values. Most studies conducted in the area of consumer socialization and materialism have employed well established measures developed and tested mostly in Western cultures. The key construct for this study (materialism) was assessed using previously published, multi-item measures using a five-point Likert format adapted from Richins and Dawson (1992) in South East Asia (Malaysia). The cross-cultural applicability of the Material Value Scale adapted for this study, as a mean of testing the scale using alternative format has proved to be reliable.

Given that peer communication and interaction plays an important role in influencing the development of materialistic values among young urban adult consumers, it is possible that other socialization agent influencers (e.g., family influence and their different forms of communication patterns with their child) may contribute to the development of materialistic values among young adults. This is because one parent's style of communication with the child (FCP) is quite different from that of the other parents. Thus, several avenues for future research are possible. We need to understand the communication processes involved in the transmission and acquisition of certain values (such as materialism) and behaviors from parent to child and how these vary by socio-demographic characteristics. The sample employed for this study has been tested in a specific cultural context alone. Given that the transmission and acquisition of values vary by socio-demographic characteristics, future studies using similar measures could be employed and tested in different cultures to better understand the impact of peer communication influences on materialism, especially among young adult consumers which has not extensively been explored in previous research related to the study of consumer socialization and values.

This study is an attempt to provide information which could be useful to help marketers to get a better understanding of their target consumers. On the other hand, this study will evoke the attention of consumer educators that young people's materialistic values are likely to get them into financial troubles. From a theoretical perspective, this study 
is an attempt to inform our ideas about consumer learning, development, and change. No other area of consumer behaviour research is so focused on the process and outcomes of consumer learning that evolve over time.

From a managerial perspective, consumer socialization research provides unique insight into the beliefs and behaviour of an important consumer segment that is young adults. Finally, from a public policy and societal perspective, there is probably no other topic in consumer research that holds more interest than socialization and the study of materialism. Government agencies and consumer groups have had an uneven history of aggressively pursuing consumer in these areas.

\section{References}

Achenreiner, G. B. (1997). Materialistic values and susceptibility to influence in children. Association for Consumer Research, 24, 82-88.

Bindah, E. V., \& Othman, M. N. (2011). The role of family communication and television viewing in the development of materialistic values among young adults. A Review. International Journal of Business and Social Science, 2(23), 238-248.

Belk, R. W. (1984). Three scales to measure vonstructs related to materialism: reliability, validity, and relationships to measures of happiness. Advances in Consumer Research, 11(1), 291-297.

Blosser, B. J., \& Roberts, D. F. (1985). Age differences in children's perceptions of message intent: Responses to television news, commercials, educational spots, and public service announcements. Communication Research, 12, 455-484. http://dx.doi.org/10.1177/009365085012004002

Chan, K., \& Prendergast, G. (2007). Materialism and social comparison among adolescents. Social Behavior and Personality, 35(2), 213-228. http://dx.doi.org/10.2224/sbp.2007.35.2.213

Chan, K., \& Zhang, C. (2007). Living in a celebrity-mediated social world: The Chinese experience. Young Consumers, 8(2), 139-152. http://dx.doi.org/10.1108/17473610710757509

Churchill, G. A., \& Moschis, G. P. (1979). Television and interpersonal influences on adolescent consumer learning. Journal of Consumer Research, 6(1), 23-35. http://dx.doi.org/10.1086/208745

Croteau, D., \& Hoynes, W. (2000). Media Society: Industries, Images and Audiences. Thousand Oaks, CA: Pine Forge Press.

Daun, A. (1983). The Materialistic Lifestyle: Some Socio-Psychological Aspects. New York: St. Martin's.

Erikson, E. H. (1968). Identity: Youth and Crisis. NewYork: Norton.

Fabris, G. (2003). IlNuovo Consumatore: Verso Il Postmoderno. Milano: Angeli.

Fox, R. W., \& Lears, T. J. J. (1983). The Culture of Consumption: Critical Essays in American History. New York: Pantheon Books.

Flouri, E. (1999). An integrated of consumer materialism: Can economic socialization and maternal values predict materialistic attitudes in adolescents. Journal of Socio-Economics, 28, 707-724. http://dx.doi.org/10.1016/S1053-5357(99)00053-0

Ganassali, S., Hennings, N., et al. (2006). Is There a Young Pan European Consumer in Theory and Practice? European Platform for Research in Marketing.

Ger, G., \& Belk, R. W. (1999). Accounting for materialism in four cultures. Journal of Material Culture, 4(2), 183-204. http://dx.doi.org/10.1177/135918359900400204

Goldberg, M. E., Gorn, G. J., Peracchio, L. A., \& Bamossy, G. (2003). Understanding materialism among youth. Journal of Consumer Psychology, 13(3), 278-288. http://dx.doi.org/10.1207/S15327663JCP1303_09

Hair, J. F., Black, W. C., Babin, B. J., Anderson, R. E., \& Tatham, R. L. (2006). Multivariate Data Analysis (6th ed). New Jersey: Prentice Hall.

Inglehart, R. (1981). Post-materialism in an environment of insecurity. American Political Science Review, 75(4), 880-900. http://dx.doi.org/10.2307/1962290

John, D. R., \& Lakshmi-Ratan, R. (1992). Age differences in children's choice behavior: The impact of available alternatives. Journal of Marketing Research, 29 (2), 216-226. http://dx.doi.org/10.2307/3172571

John, D. R. (1999). Consumer socialization of children: A retrospective look at twenty-five years of research. Journal of Consumer Research, 26(3), 183-213. http://dx.doi.org/10.1086/209559

Kasser, T. (2002). The High Price of Materialism. Cambridge, MA: The MIT Press. 
Keng, K. A., Jung, K., Jiuan, T. S., \& Wirtz, J. (2000). The influence of materialistic inclination on values, life satisfaction and aspirations: An empirical analysis. Social Indicators Research, 49(3), 317-333. http://dx.doi.org/10.1023/A:1006956602509

Korten, D. C. (1999). The Post-Corporate World: Life after Capitalism. West Hartford, CT: Kumarian Press.

La Ferle, C., \& Chan, K. (2008). Determinants for materialism among adolescents in Singapore. Journal of Young Consumer, 9(3), 201-214. http://dx.doi.org/10.1108/17473610810901624

McLeod, J. M., \& Chaffee, S. H. (1972). The construction of social reality. In J. Tedeschi (Ed.), The social influence process (pp. 50-59). Chicago: Aldine-Atherton.

McNeal, J. (1999). The kids market: Myths and realities. Ithaca, NY: Paramount Marketing Publishing.

Moore, R. L., \& Moschis, G. P. (1981). The effects of family communication and mass media use on adolescent consumer learning. Journal of Communication, 31, 42-51. http://dx.doi.org/10.1111/j.1460-2466.1981.tb00449.x

Moschis, G. P., \& Moore, R. L. (1979). Family communication and consumer socialization. Advances in Consumer Research, 6, 359-363.

Moschis, G. P., \& Mitchell, L. G. (1986). Television advertising and interpersonal influences on teenagers' participation in family consumer decisions. Advances in Consumer Research, 13, 181-186.

Moschis, G. P. (1985). The role of family communication in consumer socialization of children and adolescents. Journal of Consumer Research, 1, 898-913. http://dx.doi.org/10.1086/209025

Moschis, G. P., \& Churchill, G. A. (1978). Consumer socialization: A theoretical and empirical analysis. Journal of Marketing Research, 15(4), 599-609. http://dx.doi.org/10.2307/3150629

Moschis, G. P., \& Mitchell, L. G. (1986). Television advertising and interpersonal influences on teenagers' participation in family consumer decisions. Advances in Consumer Research, 13, 181-186.

Mukerji, C. (1983). From Graven Images: Patterns of Modern Materialism. New York: Columbia University Press.

Piaget, J. (1953). The Origin of Intelligence in the Child. New York: Routledge \& Kegan Paul Ltd.

Reimer, B., \& Rosengren, K. E. (1990). Cultivated Viewers and Readers: A Life-Style Perspective. Newbury Park, CA: Sage.

Richins, M. L., \& Dawson, S. (1992). A consumer values orientation for materialism and its measurement: scale development and validation. Journal of Consumer Research, 19(3), 303-316. http://dx.doi.org/10.1086/209304

Richins, M. L., \& Dawson, S. (1990). Measuring material values: A preliminary report of scale development. Advances in Consumer Research, 17, 169-175.

Richins, M. L. (1994). Valuing things: The public and private meanings of possessions. Journal of Consumer Research, 21(3), 504-521. http://dx.doi.org/10.1086/209414

Roberts, J. A., Manolis, C., \& Tanner, Jr, J. F. (2008). Interpersonal influence and adolescent materialism and compulsive buying. Social Influence, 3(2), 114-131. http://dx.doi.org/10.1080/15534510802185687

Robertson, T. S., \& Rossiter, J. R. (1974). Children and commercial persuasion: An attribution theory analysis. Journal of Consumer Research, 1, 13-20. http://dx.doi.org/10.1086/208577

Schor, J. B. (1999). What's Wrong with Consumer Society? Competitive Spending and the New Consumerism. Washington D.C: Island Press.

Schindler, D. R., \& Cooper, P. S. (2001). Business Research Methods (7th ed.). New York, NY: McGraw-Hill.

Schuman, H., \& Presser, S. (1981). Questions and Answers in Attitude Surveys. New York: Academic Press.

Talmon, Y. (1963). Comparative Analysis of Adult Socialization. Paper presented at the Social Science Research Council Conference on Socialization Through the Life Cycle. New York.

Thorton, R., \& Nardi, P. M. (1975). The dynamics of pole acquisition. American Journal of Sociology, 80, 870-884. http://dx.doi.org/10.1086/225897

Ward, S. (1974). Consumer socialization. Journal of Consumer Research, 1(2), 1-14. http://dx.doi.org/10.1086/208584

Ward, S., \& Wackman, D. B. (1971). Family and media influences on adolescent consumer learning. American Behavioral Scientist, 14(3), 415-427. http://dx.doi.org/10.1177/000276427101400315 
Wiggins, J. S. (1973). Personality and Prediction: Principles of Personality Assessment. Reading, MA: Addison-Wesley.

Wong, N., Rindfleisch, A., \& Burroughs, J. (2003). Do reverse-worded items confound measures in cross-cultural consumer research? The case of the material values scale. Journal of Consumer Research, 30, 72-91. http://dx.doi.org/10.1086/374697

Table 1. High Materialism and Low Materialism: A Demographic Comparison

\begin{tabular}{|c|c|c|c|c|}
\hline \multirow[t]{2}{*}{ Characteristics } & \multicolumn{2}{|c|}{$\begin{array}{l}\text { 'Low' Materialism } \\
\qquad(\mathrm{N}=527)\end{array}$} & \multicolumn{2}{|c|}{$\begin{array}{l}\text { 'High' Materialism } \\
\qquad(\mathrm{N}=429)\end{array}$} \\
\hline & Frequency & Percentage & Frequency & Percentage \\
\hline \multicolumn{5}{|l|}{ Gender $\left(X^{2}=0.000, p\right.$-value $\left.=0.997\right)$} \\
\hline Male & 210 & 39.8 & 171 & 39.9 \\
\hline Female & 317 & 60.2 & 258 & 60.1 \\
\hline \multicolumn{5}{|l|}{ Age $\left(\mathrm{X}^{2}=0.332, \mathrm{p}\right.$-value $\left.=0.954\right)$} \\
\hline $18 \&$ below & 27 & 5.1 & 25 & 5.8 \\
\hline $19-29$ & 443 & 84.1 & 356 & 83.0 \\
\hline $30-39$ & 48 & 9.3 & 42 & 9.8 \\
\hline $40-48$ & 9 & 1.5 & 6 & 1.4 \\
\hline \multicolumn{5}{|l|}{ Ethnicity $\left(\mathrm{X}^{2}=2.553, \mathrm{p}\right.$-value $\left.=0.466\right)$} \\
\hline Malay & 262 & 49.7 & 233 & 54.3 \\
\hline Chinese & 159 & 30.2 & 111 & 25.9 \\
\hline Indians & 56 & 10.6 & 46 & 10.7 \\
\hline Others & 50 & 9.5 & 39 & 9.1 \\
\hline \multicolumn{5}{|l|}{ Religion $\left(\mathrm{X}^{2}=4.706, \mathrm{p}\right.$-value $\left.=0.319\right)$} \\
\hline Islam & 302 & 57.3 & 254 & 59.2 \\
\hline Buddhism & 114 & 21.6 & 81 & 18.9 \\
\hline Hinduism & 49 & 9.3 & 41 & 9.6 \\
\hline Christianity & 48 & 9.1 & 48 & 11.2 \\
\hline Others & 14 & 2.7 & 5 & 1.2 \\
\hline \multicolumn{5}{|l|}{ Marital Status $\left(X^{2}=2.548, p\right.$-value $\left.=0.467\right)$} \\
\hline Single & 467 & 88.8 & 373 & 86.9 \\
\hline Married without children & 22 & 4.0 & 21 & 4.9 \\
\hline Married with children & 36 & 6.8 & 30 & 7.0 \\
\hline Widow/Widower/Divorcee & 2 & 0.4 & 5 & 1.2 \\
\hline \multicolumn{5}{|l|}{ Education $^{\mathrm{a}}\left(\mathrm{X}^{2}=5.399, \mathrm{p}\right.$-value $\left.=0.249\right)$} \\
\hline Primary School or Less & 0 & 0.0 & 1 & 0.2 \\
\hline $\mathrm{PMR} / \mathrm{SRP} / \mathrm{LCE}$ & 1 & 0.2 & 2 & 0.5 \\
\hline SPM/SPVM/MCE & 61 & 11.6 & 40 & 9.3 \\
\hline College Diploma & 157 & 29.8 & 150 & 35.0 \\
\hline Professionalqualification/University degree & 308 & 58.4 & 236 & 55.0 \\
\hline \multicolumn{5}{|l|}{$\begin{array}{l}\text { Monthly Gross Personal Income } \\
\left(\mathrm{X}^{2}=6.600, \mathrm{p} \text {-value }=0.252\right)\end{array}$} \\
\hline Less than RM1,000 & 348 & 66.0 & 281 & 65.5 \\
\hline RM1,000 to RM1,999 & 73 & 13.9 & 56 & 13.1 \\
\hline RM2,000 to RM3,999 & 78 & 14.8 & 57 & 13.3 \\
\hline RM4,000 to RM5,999 & 20 & 3.8 & 30 & 7.0 \\
\hline RM6,000 to RM7,999 & 7 & 1.3 & 3 & 0.7 \\
\hline RM8,000 to RM9,999 & 1 & 0.2 & 2 & 0.5 \\
\hline
\end{tabular}

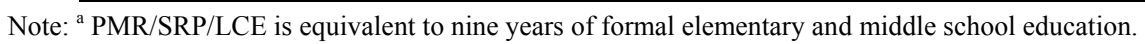


Table 2. Comparing the Mean Scores of the Peer Communication Factors

\begin{tabular}{|c|c|c|c|c|}
\hline \multirow{2}{*}{ Main Constructs } & \multicolumn{2}{|c|}{ Mean $^{\mathrm{a}}$} & \multirow{2}{*}{ t-value } & \multirow{2}{*}{ Significance $^{\mathrm{b}}$} \\
\cline { 2 - 3 } & 'Low materialism' & 'High materialism' & & \\
\hline Peer communication & 3.52 & 3.78 & -4.933 & 0.000 \\
\hline
\end{tabular}

Note: ${ }^{a}$ Higher scores represent greater agreement with the attributes; ${ }^{b}$ Level of significance using t-tests.

Table 3. Materialism Group Differences

\begin{tabular}{|c|c|c|c|c|c|c|c|}
\hline \multirow{2}{*}{ Variables } & \multicolumn{2}{|c|}{ 'Low Materialism' } & \multicolumn{2}{|c|}{ 'High Materialism' } & \multirow{2}{*}{ Wilks' Lambda } & \multirow{2}{*}{ F } & \multirow{2}{*}{ Sig } \\
\cline { 2 - 5 } & Mean & Std. Dev & Mean & Std. Dev & & & \\
\hline Peer communication & 3.52 & 2.411 & 3.78 & 2.399 & .975 & 24.337 & 0.000 \\
\hline
\end{tabular}

Table 4. Discriminant Analysis of the Two Materialism Groups

\begin{tabular}{|c|c|c|c|}
\hline Variables & Unstandardized Coefficient & Standardized Coefficient & Pooled within groups Coefficients \\
\hline Peer communication & .333 & $.738^{* *}$ & .800 \\
\hline
\end{tabular}

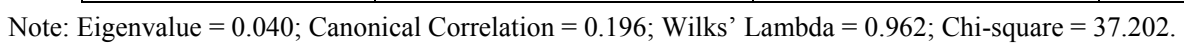

${ }^{* *} \mathrm{p}<.0000$

Table 5. Classification Results of Discriminant Analysis

\begin{tabular}{|c|c|c|c|c|}
\hline \multirow{2}{*}{ Actual Group } & \multirow{2}{*}{ Group Centroids } & \multirow{2}{*}{ Number of Cases } & \multicolumn{2}{|c|}{ Predicted Group Membership } \\
\cline { 3 - 4 } & & & 'Low materialism' & 'High materialism' \\
\hline 'Low Materialism' & -.180 & 527 & $298(56.5 \%)$ & $229(43.5 \%)$ \\
\hline 'High Materialism' & .221 & 429 & $179(41.7 \%)$ & $250(58.3 \%)$ \\
\hline
\end{tabular}

Note: $57.3 \%$ of the grouped cases were correctly classified. 